\title{
Sea -Water Intrusion Studies For Coastal Aquifers: Some Points To Ponder
}

\author{
Abhay K. Soni ${ }^{1, *}$ and Paras R. Pujari ${ }^{2}$ \\ ${ }^{1}$ Central Institute of Mining and Fuel Research, Nagpur, India \\ ${ }^{2}$ National Environmental Engineering Research Institute, Nagpur, India
}

\begin{abstract}
Researchers all over the world have contributed various scientific studies to understand coastal aquifers characteristics and to study sea water intrusions phenomenon. While evaluating the impact of sea water on ground water system near the coast some pertinent points haunt the scientific community. In this technical contribution authors has raised some burning issues and points. Though, such issues and dilemmas were emerged in the analysis and discussions in past but the error and its magnitude, reliability of analyzed data, volume and source of authenticity of input field data, practical acceptance of solutions suggested etc. are some points that need introspection. Precise and better scientific analysis and solutions may be thought for future research directions and focus can be made on some of the points and issues raised. Based on interdisciplinary approaches accuracy in "evaluation plan and procedure" can be achieved scientifically and the challenges of uncertainty of sea- water intrusion assessment can be dealt in totality. Predictions required should be done in a realistic timeframe in respect of any particular geological domain, country or specific area. In brief, this original and must to read article encompasses technical material for the entire scientific community.
\end{abstract}

Keywords: Coastal aquifers, sea water intrusions, future research areas in sea water related studies.

\section{INTRODUCTION}

Sea, a dynamic entity, is often partly enclosed by land and coastal aquifers are those which occupy these land areas in the sea vicinity. Coastal aquifers have site-specific characteristics (Bear et al. 1999) [1] and differ from other aquifers in terms of characteristics parameters. Industrial establishments located, on and around the coastal aquifers, impact these aquifers in various magnitudes which may be either positive or negative. Hence, the need for evaluation of coastal aquifers has always been felt. But, their evaluation is an intricate issue to any hydro-geologist.

In this technical contribution authors have tried to raise some valid and reasonable points with a view to ponder. Their detailed analysis could help to answer some pertinent technical questions which haunts to the end user world over and therefore scientific community must think and do introspection about it. The points raised here are written in a simple and easy to understandable terms only. Complex technical terms and equations etc. have been avoided as far as possible for the ease of the reader as the objective of achieving the direction for future work is the ultimate aim of the article and not about the method and manner of investigation.

Since the challenges of uncertainty is often quite high and the obtained evaluation results are not very close the accuracy, search for the answer of these question are needed irrespective of any particular geological domain, any country

*Address correspondence to this author at the Central Institute of Mining and Fuel Research, Nagpur, India; Tel: +91 712 2510253;

Fax: +91 712 2510311, 2510604; E-mail: abhayksoni@gmail.com, kallioras@geo.tu-darmstadt or any specific area(s). Coastal hydro-geology has large amount of uncertainty due to two facts:

(a) The dynamism of sea and hydrological principle of water flow and movement has linkages, which remained unanswered fully.

(b) The science involved in such evaluation (i.e. geological science, rock engineering science and ground water science) is dependent on the actual field conditions encountered and parametric variations that exist is significant and large making the precise and to the point evaluation as difficult and cumbersome.

\section{THE PHENOMENON}

Seawater intrusion is a natural process that occurs in virtually all coastal aquifers and limited to coastal areas only. It consists of salty water inflow from the sea towards freshwater aquifers and flowing inland. This inflow behavior is caused by the fact that seawater has a higher density (because seawater carries more solutes) than freshwater. An imagery line called interface is developed all along and earmark the sea-water fresh water interaction. The first and oldest physical formulations of saltwater intrusion were made by W. Baydon-Ghyben $(1888,1889)$ and A. Herzberg (1901) and referred as the Ghyben-Herzberg formulation. They derived analytical solutions to approximate the intrusion behavior, which are based on a number of assumptions that do not hold in all field cases. The GhybenHerzberg ratio states, for every foot of fresh water in an unconfined aquifer above sea level, there will be forty feet of fresh water in the aquifer below sea level (Karant, 1990) [2].

Salinity (Higher TDS concentration), temperature, rocks heterogeneities, solute transport (density dependent flow) 
and aquifer characteristics namely hydraulic conductivity, transmissivity are some key technical parameters that effect the performance of coastal aquifers and sea - water intrusion phenomenon.

In some areas, coastal hydro-geologic condition is represented by an individual confined, unconfined or island aquifer system whereas in other cases the hydro-geologic setting may be that of a multi-layer aquifer system. In either situation, the aquifer system has a sea front so that there is a direct contact between continental freshwater and marine saltwater. Besides difference in viscosity between the two fluids, there exist density changes as well, which depends mainly on the salinity differences (TDS concentration). Under natural, undisturbed conditions, a seaward hydraulic gradient exists in the aquifer with freshwater discharging into the sea. The heavier saltwater flows in from the sea and a wedge-shaped body of saltwater develop beneath the lighter freshwater, with the freshwater thickness decreasing from the wedge towards the sea. The freshwater/saltwater interface is stationary under steady state condition with its shape and position determined by the freshwater head and gradient.

\section{POINTS TO PONDER}

Saltwater intrusion is a natural process, and bound to occur but it becomes an environmental problem when excessive pumping of fresh water from an aquifer takes place (Soni and Pujari, 2010) [3]. This situation arises in nearly all those coastal areas which are populated. The ultimate effect of overexploitation of ground water intensifies the effect of salt water intrusion into fresh and new areas and developing countries are largely impacted as they have significant coastal area population.

The fact that saltwater intrusions mechanism is difficult to understand fully is because of variable natural factors and dynamic characteristics of involved parameters (CMRI, 2007) [4]. Scientific community needs introspection on the points given below for better understanding of seawater intrusion phenomenon -

a In coastal aquifers, the investigation of groundwater flow at regional scale is complicated because the relatively minor spatial variation in groundwater density has a substantial effect on groundwater flow rates and patterns. An understanding of variable-density ground water flow, therefore, is important in studies of seawater intrusion and contaminated site remediation.

b Aquifer Dynamics tend to be pretty slow and it takes the 'intrusion cone' a long time to adapt to changes if any in pumping schemes, rainfall, etc. So the situation in the field is sharply and significantly different from what is considered theoretically How to answer this is a point to think?

c A mixture of saltwater - freshwater is often remaining under saturated condition with respect to calcium, triggering dissolution of calcium in the mixing zone and changing the hydraulic properties. This needs analysis from scientific angle.

d Does the ground water pumpage rate is sufficient enough to produce significant movement of interface or is it dependent on time and other factors needs to be searched in detail? e The process known as 'Cation Exchange' which slows the advance and retreat of the saltwater intrusion mechanism is not incorporated and evaluated properly.

f Does the basic Ghyben-Herzberg ratio of 1: 40 - fresh water: saltwater for an unconfined aquifer above sea level hold good in all conditions practically or else it requires modification?

g When freshwater levels drops with season, the intrusion proceed further inland. This problem need more research angle investigation i.e. field data authentication.

h Salinity concentration data used for sea water intrusion are extremely sensitive to flow direction and its pattern. It is observed that intrusion occurs in some cases. This is one demanding area for future research.

Until the year 2000, there were four recognized oceans namely the Pacific, Atlantic, Indian, and Arctic. In 2000, the International Hydrographic Organization delimited a new ocean, the 'Southern Ocean'. It surrounds Antarctica and extends to 60 degrees latitude ${ }^{1}$. Since the existing literature is deficient and there is very limited studies carried out in this newly formed oceanic part. Future directions of study should be directed towards 'Southern Ocean'.

Characteristics of Aquifers: In different parts of the world, the characteristics of coastal aquifers vary. Since these characteristics are the determinant parameters for technical assessment, their evaluation accuracy and method by which determined in the field is significantly important. Some questions generally haunt the evaluator -

a How accurate are the characteristics parameters, particularly those which controls ground water flow e.g. transmissivity and hydraulic conductivity? Are they close to the actual?

b How the dynamism of sea impact on the characteristics / properties and whether taken into account properly or not?

c The role or the relation that exists between geological structures, their complexities and aquifer characteristics are embedded in the study at the micro level or macro level and whether defined correctly as input parameters for evaluation.

Fresh Water - Saline Water Interface: Number of hydrogeologists and researchers world over explained the interface development and movement phenomenon. Certainly, industrialization, ground water extraction and recharge, uses of water in coastal areas has relation with interface movement (Ginsberg and Levanton, 1976) [5].

Inland changes in recharge or discharge modify the flow within the freshwater region inducing a corresponding movement of the interface. A reduction in freshwater flow due to overdraft causes the interface to move inland. Conversely, the interface retreats following an increase in freshwater flow. The extent of intrusion or more precisely, interface movement also depends on many other factors such as tidal effects of sea, climatic conditions, flow pattern etc.

\footnotetext{
${ }^{1}$ http://www.enchantedlearning.com/subjects/ocean
} 
Therefore, interdisciplinary approach and scientific accuracy in their evaluation considering related parameters is essential. One question which arises in the inquisitive mind of any researcher - Does the ground water pumpage rate is sufficient enough to produce significant movement of interface or is it dependent on time and other factor which is generally ignored in evaluation?

Sea-water intrusions modeling evaluation results should be linked with socio-economic parameters for effective management in coastal regions. This point needs attention towards implementation practices which can be done by more intensive $R \& D$ input. The agricultural practice, especially the ground water use, has a significant role in the intrusion understanding.

Prediction of sea water intrusion beyond 30 years is an R\&D exercise of no factual interest for practical purposes as the socio-economic conditions and land use practices are going to be changed in such a long period. Therefore, the assessment and management should be done not beyond 30 years. However, only for academic interest one may have longer assessment period (Pujari and Soni, 2008)[6].

For long-term prediction models, the future climate scenario constitutes a bigger uncertainity and forms a big unknown. Changing climate conditions versus land use practices has bearing effect on the phenomenon and the practices. How to cope this uncertainty should be thought of by researchers and more $R \& D$ impetus is required in this area?

The recent phenomenon of Sea Level Rise and its impact on intrusion phenomenon is still not much explored, though some noted studies were done in USA and advanced countries. According to an estimate the use of ground water accounts for $0.8 \mathrm{~mm}$ sea level rise (DTE, 2010) [7]. As we exploit coastal aquifers more water becomes part of the hydrological cycle and wind up in the sea. Therefore, it should be properly and scientifically explained and later incorporated in modeling and evaluation procedure of intrusion.

As regards with coastal areas, aquifer boundaries and the hydrologic and structural properties of aquifers are extremely important from the evaluation point of view though they are not the aquifer parameters representing the characteristics. The later i.e. hydrologic and structural properties are since rocks related and not homogenous; researchers find it difficult to consider them to an extent as they should be. In brief, considering geological parameters for assessment of geology of coastal aquifers becomes complex for scientific evaluation (Ebraheem et al.,1997; Amer,1995; Choudhury et al., 2001) [8-10].

In the 20th century, the higher computing power allowed the use of numerical methods, usually, FED (finite differences) or FEM (finite elements) for saltwater intrusion studies as these are very easy to use and versatile tools. Beyond doubt, mathematical modeling of sea water intrusion is a practical and easy to use tool to understand the nature and severity of salinity problem in coastal aquifers but how much close the results are with observed field conditions, is yet to be understood fully? Observations mentioned in Table $\mathbf{1}$ could be helpful for refinement of various evaluation tools and techniques and removing some practical difficulties in searching exact numerical solutions through experience.
The mathematical analysis of the variable-density saltwater intrusion problem at regional scale may involve several simplifying assumptions (Ghosh and Sharma, 2006) [11]. Depending upon whether the freshwater and saltwater are taken as miscible or immiscible fluids. There are two distinct approaches to model a coastal aquifer system namely Sharp Interface Approach and Miscible Transport Approach. The later one is more popular compared to former.

a The sharp interface approach, which assumes that freshwater being immiscible fluids are separated by an abrupt interface, is suitable when the width of transition zone is small relative to the thickness of the aquifer. For a thicker transition zone, the miscible transport approach is adopted, which accounts for the effects of hydrodynamic dispersion and represents the transition zone. In miscible transport models, the problem of seawater intrusion is posed as that of a variable-density fluid flow accounting for the effects of dispersion. These models requires the simultaneous solution of the coupled groundwater flow and advective-dispersive equations (Bear, 1979) [12].

b The miscible transport approach is adopted in areas where the transition zone is wide (Howard and Mullings, 1996) [13]. When concentration gradients are low, the governing equations can be solved aerially on a basin-wide scale. However, when the flow is density dependent, the vertical dimension must be included. Because of computational constraints, studies based on this approach have been generally limited to twodimensional vertical cross-sections. While simulating the movement of a narrow concentration front, some numerical instabilities and errors may occur, especially in areas where the transition zone approaches a sharp interface. In this way, a regional scale study of saltwater intrusion is a complex exercise needing further in-depth studies.

Larger TDS concentration of ground water near sea causes higher or increased rate of salinization due to significant density contrast. Such concentration gradually decreases with distance from sea. Therefore, the results of simulation etc. need a volume of field data for formal accurate assessment (Hughes et al. 2010) [14].

High resolution geophysical imaging techniques which are non-invasive in nature could be helpful in better understanding the salt water intrusion at varying scale. Thus, the possibilities of the advanced techniques in this direction are immense and needs to be explored in future (Sheriff, 2010) [15].

Cost Effective Control and Management: Coastal area pollution in terms of salt water intrusion requires intervention to arrest its inland advancement and thus requires management techniques. Injection barriers, extraction barriers, physical barriers, tapping alternative aquifers in vicinity / closely, well relocation, modified pumping schedule,demand management, conjunctive use, aquifer storage and recovery, desalination (treatment of saltwater) are some management techniques which are applied. Broadly these can be categorized as "Conventional Methods" and "Innovative Engineering Methods". They are basically regulatory approaches of managing ground water in 
Table 1. Evaluation Tools and Techniques

\begin{tabular}{|c|c|}
\hline The Parameters & Observation \\
\hline Assumptions in Modelling & $\begin{array}{l}\text { Critical assumptions are made in modelling of sea water intrusion which has bearing } \\
\text { on overall results. To maintain uniformity in choosing various assumptions, an em- } \\
\text { pirical scale or monogram like scale, based on various rock types should be formu- } \\
\text { lated and developed. This will form as future research work area. }\end{array}$ \\
\hline Assignment of Values to Aquifer Parameters & $\begin{array}{l}\text { The approach for assigning aquifer parameter values that pertain to groundwater flow } \\
\text { and solute transport is based on experience of modeler, engineering judgments and to } \\
\text { use the simplest distribution that would result in adequate representation of the flow } \\
\text { system. All parameter values are adjusted during the model calibration process until } \\
\text { the model adequately reflected the observed water level distribution and interpreted } \\
\text { flow patterns throughout the aquifer. Such uniform condition does not exist through- } \\
\text { out the aquifer and hence the estimated results are not close to reality }\end{array}$ \\
\hline Boundary conditions & $\begin{array}{l}\text { There exists an ample scope of manual error in defining the boundary conditions in } \\
\text { view of no fixed norms. Each team of evaluator assigns different values as per the } \\
\text { ground elevation and the priority of the water body present in vicinity e.g. river etc.. } \\
\text { The values considered in this regard is thus widely variable (Soni and Pujari, } 2008 \\
\text { [6] and CMRI, 2007 [4]). }\end{array}$ \\
\hline Internal Hydrologic Stresses & $\begin{array}{l}\text { Hydrologic stresses that are internal to the model domain are represented with inter- } \\
\text { nal boundary conditions. Internal hydrologic stresses include, recharge from rainfall, } \\
\text { return flow, and water withdrawals. These dependent parameters are related with the } \\
\text { mathematical equations used in computation and its accuracy. }\end{array}$ \\
\hline Recharge and Return flow & $\begin{array}{l}\text { The general procedure for estimating recharge values is to multiply the average an- } \\
\text { nual rainfall quantity in each zone by infiltration coefficient. The infiltration coeffi- } \\
\text { cient is estimated according to soil type, land use and evapo-transpiration rate. The } \\
\text { average rate of recharge considered for modeling quite differs from the actual be- } \\
\text { cause of uncertainty. } \\
\text { Agriculture pumping figures and return flow within the area and in any given year } \\
\text { depends on factors such as methods of agriculture practiced, irrigation methods, crop } \\
\text { and soil types and schedules adopted. The estimation done is based on population } \\
\text { and its growth, number of wells, and groundwater abstraction rates. } \\
\text { Since a portion of the pumped water infiltrates back into the aquifer ( in agriculture / } \\
\text { irrigation) and there is no accountability of such return flow, the input data becomes } \\
\text { incorrect. Secondly, ground water pumping data of municipal, irrigation and agricul- } \\
\text { tural well fields are also not very accurate thus affecting the accuracy. Significant } \\
\text { and large variability exists in Ground Water Recharge and the considered values are } \\
\text { not close to the real. }\end{array}$ \\
\hline Calibration and Model Results & $\begin{array}{l}\text { The numerical models are calibrated and tested against observed data. Verification of } \\
\text { the model is done based on the average water level and time varying target condition. } \\
\text { The calculated residual mean error and absolute mean error in general should shows } \\
\text { compatibility when evaluated using different evaluation but it differs very widely and } \\
\text { as per the models. This put a damper on the mind of assessor and field personnel } \\
\text { whether the results are correct or not. } \\
\text { Calibration of models makes some assumptions. How close they are with realistic } \\
\text { conditions is a point for discussion and analysis. }\end{array}$ \\
\hline Interpretation of Simulation Results & $\begin{array}{l}\text { In order to demonstrate the effect of future scenarios of groundwater pumpage on } \\
\text { seawater intrusion, pumping scheme are designed and planned which in reality does } \\
\text { not hold good causing erroneous predicted result of the calibrated model used in the } \\
\text { study. The simulation results shows the appearance of dry cells, layer wise and in } \\
\text { upper layer after certain years of simulation period, if continuous extraction of water } \\
\text { with the same rate of withdrawal is practiced. Such assumption, about continuously } \\
\text { increase or decrease of pumpage rate and the simulation period influences the results } \\
\text { interpretation. Hence, the period of prediction and simulation should be realistic in } \\
\text { practical sense. }\end{array}$ \\
\hline
\end{tabular}

coastal areas. Are these techniques cost effective for implementation? More and more countries should develop and design new control methods, improved monitoring schemes and simple numerical models for assessment. Techniques so developed, should be practically usable and less costly (Barlow and Reichard, 2010) [16].

Coastal aquifers being the lifeline and target of subsistence for very large section of population all over the world their management, conservation and monitoring is of utmost importance. Particularly, the monitoring of such aquifers is often neglected. Careful and more attention towards monitoring should be done and results should be derived in a scientific manner.

It is essential that 'piezometers' be installed in all the coastal aquifers permanently and monitoring be carried out for key parameters like water level, electrical conductivity of ground, sodium $(\mathrm{Na})$, chloride $(\mathrm{Cl})$ and bi-carbonate $\left(\mathrm{HCO}_{3}\right)$ content of ground water etc. A long-term monitoring plan of 


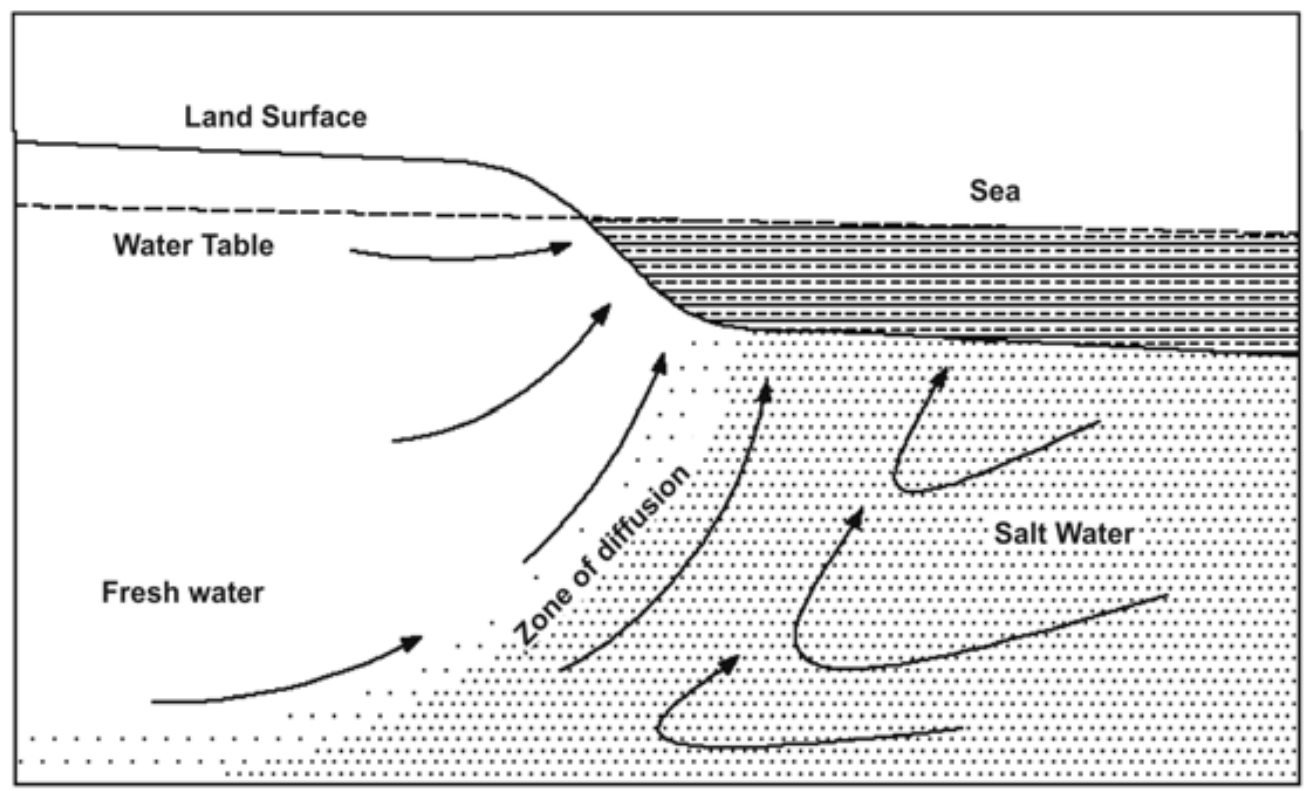

Fig. (1). Zone of transition diffusion in a coastal aquifer (Todd, 1980) [25].

these parameters would be useful for better evaluation and understanding.

Accreditation: The subject area of sea water intrusion is complicated. Therefore, accreditation of investigators, consultants as well as implementing personnel is extremely essential as without the full knowledge, the chances of committing error is more pronounced. The professionally qualified personnel, who perform the investigation, must have updated education, training and experience. Not only that he /she should adhere to the code of practices and ethical standards (Brown, 2010) [17]. In such highly technical area, no specific certification mechanism for professional exists. However, certified national and international professionals and engineers who have in-depth knowledge of geology and hydrology and are conversant with the science and mechanism of the subject area is a good choice.

Does all soft computing tools i.e. software, simulation and modelling tools etc. perfectly evaluate the phenomenon and shows the correct results? How close they are with the actual conditions encountered in field? e.g. the possible presence of small- scale heterogeneities in the rock that plays an important role in determining the hydraulic properties of the aquifers are too small to be taken into account by the modelling tools is a one grey area to search for answer (Guo and Langevin, 2002 and Langevin et al., 2003) [18, 19].

Water table and its height in immediate sea vicinity are not adequately explained by the scientific community. At some places, when the fresh (and sweet) ground water is found near the sea (may be at depth more than 200m) the proper scientific explanation is not found in literature. Many a times its need is felt (Ragunath, 1997) [20].

Pollution of Coastal Aquifers: (a) Lenses and Pockets of ground water in coastal areas are more vulnerable from pollution angle. Specific studies, which are concentrated towards such type areas are required for different geological set up and conditions (White and Falkland, 2010) [21]. (b) Role of Biological Components /Microbes in Contamination of
Coastal Ecosystems' is one new and unexplored area within the sea water intrusion studies which need attention in future.

Statuary Compliance: In many countries, there are restrictions posed by the government to install industries closer to the coastal areas e.g. In India such restrictions exist in the form of Coastal Regulation Zones (CRZ) and Coastal Zone Management (CZM) and restricted distance is $500 \mathrm{~m}$ from the sea coast (DTE, 2008) [22]. Near coast, various categories of zones exists e.g. CRZ I, II III etc. which have designated management norms. Sometimes, the statuary compliance of such restrictions is not evaluated technically and thereby mismatches with the field conditions. Thus, evaluated technical results are not in consonance. This poses implementation difficulty.

Along with statuary compliance the technical issues should be addressed in such a way that the law of the land should be adhered to. It is noted that, economical, social and political issues of coastal area management dominate over technical and environmental issues and adequate groundwater development is not given due consideration. This needs attention, adequately.

Challenges of Uncertainty: High variability, complex solution and unclear / poor definition of parameters is a source of uncertainity for evaluations in multiple technical areas of sea water intrusion assessment. It could be met out with more intensive knowledge based interaction e.g. coupled density dependent flow through analysis and modelling approaches, reactive transport codes etc.

Seawater intrusion occurs mainly on account of saltwater transport by advection and hydro-dynamic dispersion (Nowroozi et al. 1999) [23]. In reality, due to hydro-dynamic dispersion, the zone of contact between freshwater and saltwater takes the form of a transition zone (or disperse interface), across which the salt concentration and hence density of water increases from that of the transition zone. This induces a cyclic flow of saltwater from the sea to the transition zone and finally back to the sea (Fig. 1). 
In some instance, the transition zone is thin, a few meters or less, but in other situations it can attain a thickness of more than a hundred meters, especially in highly nonhomogeneous formations (e.g. limestone aquifer). In nonhomogeneous highly permeable materials, with small freshwater flow, the top of the transition zone can reach the water table (Shammas and Jacks, 2007) [24]. Moreover, the thickness of transition zone is not constant, and may expand or contract in accordance with a succession of low and high tides and wet and dry periods. Thus, mechanism of saltwater transport is quite cumbersome to interpret in actual filed conditions. Both for researcher and for the implementing agency the uncertainty involved is very high.

The Geochemistry of Sea Water: Sea / Ocean water is naturally alkaline and has $\mathrm{pH}$ of 8.0 - 8.3. The complex spectrum of macro and trace minerals found in sea water is the result of the interaction of natural forces over millions of years; a process not yet fully understood by scientists. A significant feature of sea water is that while the total concentration of dissolved salts varies from place to place, the ratios of the more abundant components remain almost constant. Many of the characteristics of sea water correspond to those of water in general, owing to their common chemical and physical properties e.g. the molecular structure of sea water resembles like that of fresh water and favors the formation of bonds among molecules. However, some of the distinctive qualities of sea water are attributable to its salt content. Followings are important to note -

- The trace elements of sea water forms a complex long chain molecule It represents a dynamic structural system of elemental combinations (Saxena et al. 2005) [26].

- The internal resistance to flow is higher than that of fresh water because of its higher salinity. Therefore, the density of sea water also is also higher.

- Sea water's freezing point is lower than that of pure water and its boiling point is higher.

- It has significant electrical conductivity in comparison to distilled water, which is a poor conductor.

- Apart from its stores of sodium chloride, sea water also constitutes a rich source of other commerciallyimportant chemical elements such as magnesium and bromine. The complex mixture of minerals and liquid that make up sea water consists of 96.5 per cent water, 3.4 per cent salts, and smaller amounts of other substances including dissolved inorganic and organic materials, particulates, and a few atmospheric gases. It is the various salts that give sea water its taste (Saxena et al., 2004) [27].

Thus, geo-chemistry of sea water and its flow in rock media needs understanding in depth to define it through complex integral equations scientifically. It should not be under estimated.

Hydro-dynamic Equilibrium: The chemical composition of sea water is influenced by a wide variety of chemical transport mechanisms. Rivers add dissolved and particulate chemicals to the oceanic margins, and windborne particulates are carried to ocean regions thousands of kilometers away from their continental source. Hydrothermal solutions that have circulated through crustal materials beneath the sea floor add both dissolved and particulate materials to the ocean. Organisms in the upper ocean convert dissolved materials to solids, which eventually settle at greater depths. Particulates in transit to the sea floor, as well as materials both on and within the sea floor, undergo chemical exchange with the surrounding solutions. Through these local and regional chemical input and removal mechanisms, each element in the oceans tends to exhibit spatial and temporal concentration variations. Physical mixing in the oceans (thermo-haline and wind-driven circulation) tends to homogenize the chemical composition of sea water. The opposing influences of physical mixing and of bio-geochemical input and removal mechanisms result in a substantial variety of chemical distributions in the oceans. Thus, hydro-dynamic equilibrium of sea water and hydrology of coast area water has some interrelationship which is not explained in literature and needs future attention.

Development of "National Guidelines for Sea-water Intrusion Assessment and Management" is the need of future for those countries which has long coastline with human concentrated activities (FAO, 1997) [28]. State of knowledge of coastal aquifer in some developing countries is very poor. An improvement for industrial needs is a point to ponder.

\section{CONCLUSIONS}

To prevent intrusion of the seawater into the main land areas of aquifer, limited groundwater withdrawal is the best possible solution. Groundwater in coastal areas can act as a stable water source but requires diligent management. Better understanding of coastal aquifer is needed to mange them more effectively. Considering various burning issues as mentioned in this research paper there exist a scope for future research with an introspection on "evaluation plan and procedure" which must be based on interdisciplinary approach, scientific accuracy and source of authenticity. The precise and cheaper way of managing should be evolved by research. If this is coupled with the managing will and skills, required targets can be achieved. Hence, it can be concluded that the future domain of coastal hydrogeology, which will be multidisciplinary in nature, will consist of hydrogeologist, geo-chemist, geologists, engineers, earth and environmental scientists and oceanographers.

\section{CONFLICT OF INTEREST}

The authors confirm that this article content has no conflicts of interest.

\section{ACKNOWLEDGEMENT}

Declared none.

\section{REFERENCES}

[1] Bear J, Cheng AH-D, Sorek S, Ouzar D, Herrera I. Seawater intrusion in coastal aquifers: concepts, methods and practices. The Netherland: A Kluwer Academic Publication 1999; p. 631.

[2] Karant KR. Ground water assessment, development and management, chapter-8 on saline water intrusion. New Delhi: TataMcgraw -Hill Publishing Company 1994; pp. 276 -94.

[3] Soni AK, Pujari PR. Ground water vis- a- vis sea water intrusion analysis for a part of limestone tract of Gujarat Coast, India. J Water Resour Prot 2010; 2: 462-8.

[4] CMRI. Geo-hydrological studies for Kovaya Limestone Mine of Ulltratech Cement. A Technical Report. Australia: Central Mining 
Research Institute (CMRI); Ref. No GC/MT/N/18/05-06, March 2007; p. 103.

[5] Ginsberg A, Levanton A. Determination of salt water interface by electrical resistivity sounding. Hydrol Sci Bull 1976; 21: 561-8.

[6] Pujari PR, Soni AK. Sea water intrusion studies near Kovaya Limestone mine, Saurashtra Coast, India. J Environ Monit Assess 2009; 154(1-4): 93-109.

[7] DTE. Down to Earth (DTE), A science and environment fortnightly. New Delhi: Society for Environmental Communications 2010; pp. 42-3.

[8] Ebraheem AAM, Senosy MM, Dajab KA. Geo-electrical and hydro-geochemical studies for delineating groundwater contamination due to salt-water intrusion in the northern part of the Nile Delta, Egypt. Groundwater 1997; 35: 216-22.

[9] Amer AM. Saltwater intrusion in coastal aquifers. Proceedings of the international conference on water resources management in arid countries. Muscat: Sultanate of Oman 1995; vol. 2, pp. 521-9.

[10] Choudhury K, Saha DK, Chakraborty P. Geophysical study for saline water intrusion in a coastal alluvial terrain. J Appl Geophys 2001; 46: 189-200.

[11] Ghosh NC, Sharma KD. Ground water modelling and management. New Delhi: Capital Publishing Company 2006; p. 594.

[12] Bear J. Hydraulics of groundwater. New York: McGraw-Hill 1979.

[13] Howard KWF, Mullings E. Study of groundwater flow and saline water in the Clarendou basin, Jamaica. Groundwater 1996; 34: 80110 .

[14] Hughes JD, Langevin CD. Goswami LB. Effect of hyper saline cooling canals on aquifer salinization. Hydrogeol J 2010; 18(1): 247-60.

[15] Sheriff M, Kacimov A, Ebraheem A, AlMulla M. Threedimensional mapping of seawater intrusion using geophysical methods, Proceedings of 8th Symposium on Groundwater Hydrology, Quality, and Management, In Section of Groundwater Council. World Environment and Water Resources Congress; 2010 May 16-20; Rhode Island: USA 2010; pp. 1136-45.
[16] Barlow PM, Reichard EG. Saltwater intrusion in coastal region of North America. Hydrogeol J 2010; 18(1): 25-38.

[17] Brown A. reliable mine water technology. J Mine Water Environ 2010; 29: 85-91.

[18] Guo W, Langevin CD User's guide to SEAWAT: A computer program for simulation of 3D variable density ground water flow. US Geol Surv 2002; 1: 430.

[19] Langevin CD, Shoemaker WB, Guo W. MODFLOW -2000, the US Geological Survey modular ground water model: SEAWAT 2000 with variable density flow process version (VDF) and the integrated MT\#DMS transport process (IMMT). US Geol Surv 2003; 3: 426 .

[20] Ragunath HM. Ground water, sea water intrusion, Chapter- 7. New Delhi: Wiley Eastern Limited 1982; pp. 217-31.

[21] White I, Falkland T. Management of freshwater lenses on small Pacific islands. Hydrogeol J 2010; 18(1): 227-46.

[22] DTE. Down to Earth (DTE). A science and environment fortnightly. New Delhi: Society for Environmental Communications 2008; pp. 21-7.

[23] Nowroozi AA, Stephen BH, Henderson P. Saltwater intrusion into the freshwater aquifer in the eastern shore of Virgina: A reconnaissance electrical resistivity survey. J Appl Geophys 1999; 42: 1-22

[24] Shammas MI, Jacks G. Sea water intrusion in the Salalah plain aquifer, Oman. Environ Geol 2007; 53: 575-87.

[25] Todd DK. Ground-water hydrology. $2^{\text {nd }}$ ed. New York: John Wiley and Sons 2007; p. 535.

[26] Saxena VK, Singh VS, Mondal NC, Maurya AK. Quality of groundwater from Neil Island, Andaman \& Nicobar, India. J Appl Geochem 2005; 7: 201-6.

[27] Saxena VK, Mondal NC, Singh VS. Evaluation of hydrogeochemical parameters to delineate fresh groundwater zones in coastal aquifers. J Appl Geochem 2004; 6: 245-54.

[28] FAO. Seawater intrusion in coastal aquifers: guidelines for study monitoring and control. USA: Food and Agricultural Organization (FAO), United Nations - Land and Water Development Division 1997; p. 156.

(c) Soni and Pujari; Licensee Bentham Open.

This is an open access article licensed under the terms of the Creative Commons Attribution Non-Commercial License (http://creativecommons.org/licenses/by-nc/3.0/) which permits unrestricted, non-commercial use, distribution and reproduction in any medium, provided the work is properly cited. 